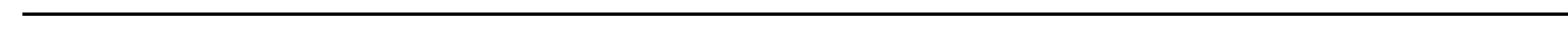

$-2$ 
OD QXVFUL SQR PEHU

$7 \mathrm{LWOH}$

\$UWLFOHSH
$\$ 1,5(3 B B$

)DFWRWMIHFWLLRZFRORVWUIXPOGQGRPSRVLWLBQGNKHURSDFRQSLJOHW JURZWRQGKHDOWK

5HVHDUFBDSHU

\$EVWUDFW

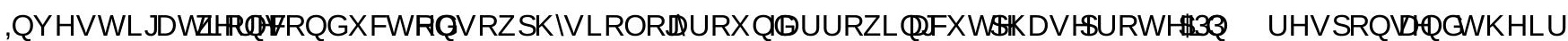

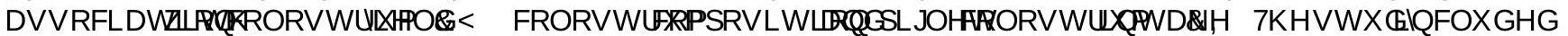
VRZVZLWK OLYHERGIQJOHWURPILYHLQQL VRQGRQHXWFIVRZKHUGGRZ IDUURZLEDVVXSHUYLVBIGG

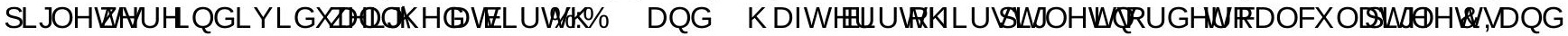
VRZ\& < \&RORVWLQXAVULWERPSBRILWLREPXQRJOREXQIL VHUXPPIORL\$ 6\$\$ DQGXSWRJORESQ FRQWHQAAVHDVVHVVHRRZ SODVPE\$\$ +S DQGSURJHVWHURQRXQGUURZLDHUHDOVRVVHVVHEGOHFWHOU

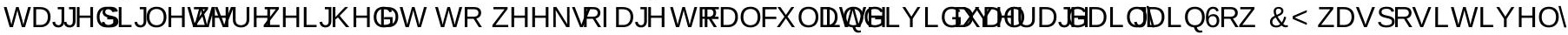
FRUUHODXVHARODVPBS 3 DQGQXPEHURI OLYHERQQJOHWB/V $\$ Q$ DGGLWLRQQQWRIIDUURZLQJ

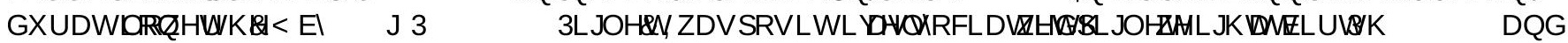

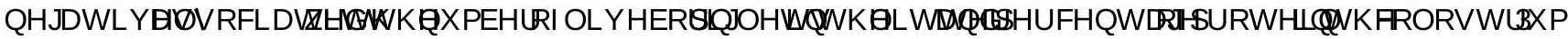

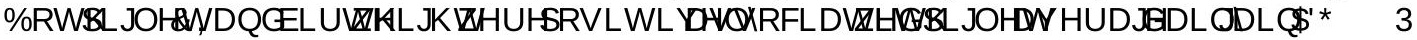
3LJOHMKUYL YDTPPELUWKHEHDQLQGHSHQGRQ\&,

.HIZRUGV

$7 D[R Q R P I$

\&RUUHVSRQGL\$WWRU

2UGHLRI \$XWKRUV

6XJJHVWH@JHY LHZHUV

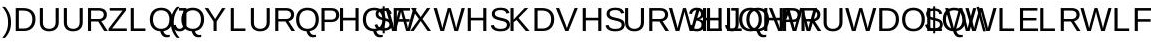
\%LRFKHPLVIAULLFXWXUH $6 K D K+D V D Q$ 6KDK+DVDQ7RRPDV 2UUR\$QQD9DOUR6DPL -XQQLNNDEDORHOWRQLHPL \&ODXGRQLYLHUR

1LFRODHYLOOHEDDqQHXXVVQHO

\section{XEPLVVLRQLOHVQFOX GHGQW K L3/)}

)LOHDPH >)LOHISH@

\&RYHUHWWHUGRFRYHHWWHU@

+LJKOLJKWVG形[LJKOLJKWV@

+DVDQHDOB\& DQGSLJOHWVGRÆDQXVFULISTH@

)LJXUHWLI >)LJXUH@

)LJXUHWLI >)LJXUH@

)LJXUHWLI >)LJXUH@

\&RQIOLRM,QWHUHVWERRQIORFYQWHUHVW@

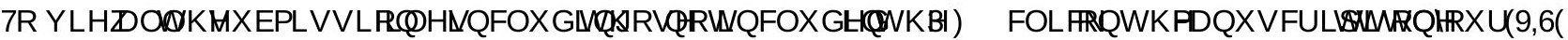
+RPHSDJH WKHELLFRZQRDGLSILOH

\section{HVHDUFKD W DSHODW HKGPW K LOK EPLV V LRQ}

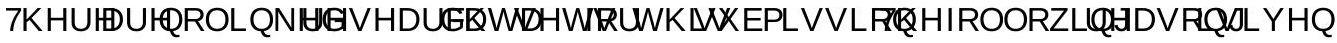

1R GDWEDVXVHGRUVKHHVHDUGEVFULEHQVNKBUWLFOH 


\section{Dear Editor,}

First of all, we are glad to submit our research article to Animal Reproduction Science .

This study investigated different sow's and piglets' related factors affecting sow colostrum yield (CY), colostrum quality and subsequent litter performance. We think this work can give a good input in the evolving research in the pig reproduction, management and welfare.

We have no previous interactions about this manuscript with an Academic Editor of this Journal, and no specific opposed reviewers.

Being aware of their outstanding work done in this specific field, we would like to suggest Nicolas Devillers (nicolas.devillers@agr.gc.ca) and Hélène Quesnel (helene.quesnel@ rennes.inra.fr) as possible reviewer of this manuscript.

On behalf of all co-authors,

Shah Hasan 
Highlights

1. A prolonged duration of farrowing and low $\mathrm{Hp}$ in sow plasma decreased sow $\mathrm{CY}$.

2. Insufficient $\mathrm{Cl}$ could lead to a significant increase in piglet mortality until weaning.

3. W eaning weights of the piglets were found to be dependent on $\mathrm{Cl}$.

4. High body reserves are important at the start of lactation for the piglet growth and survivability. 
1 Factors affecting sow colostrum yield and composition, and their impact on piglet growth and

2 health

3 Shah Hasana*, Toomas Orro ${ }^{b}$, A nna V alros ${ }^{a}$, Sami J unnikkalac, Olli Peltoniemia Claudio Oliviero ${ }^{a}$

4 aD epartment of Production A nimal M edicine, Faculty of V eterinary M edicine, 00014 University of

5 Helsinki, Finland.

6 bInstitute of V eterinary M edicine and A nimal Sciences, Estonian U niversity of Life Sciences, Tartu

7 51014, Estonia

8 'D epartment of V eterinary Biosciences, Faculty of $V$ eterinary M edicine, 00014 U niversity of

9 Helsinki, Finland.

$10{ }^{*}$ Corresponding author: Shah Hasan, shah.hasan@ helsinki.fi

11 A bstract

12 Investigations were conducted on sow physiology around farrowing, acute phase protein (A PP)

13 response and their association with colostrum yield $(\mathrm{CY})$, colostrum composition and piglet 14 colostrum intake $(\mathrm{Cl})$. The study included 229 sows with 3,210 live-born piglets from five Finnish

15 and one Dutch sow herds. Sow farrowing was supervised, and piglets were individually weighed at 16 birth $\left(B W_{B}\right)$ and $24 \mathrm{~h}$ after birth of first piglets in order to calculate piglets $\mathrm{Cl}$ and sow $\mathrm{CY}$.

17 Colostrum nutritional composition, immunoglobulin ( $\mathrm{g}$ ), serum amyloid A (SA A) and haptoglobin $18 \mathrm{Hp}$ contents were assessed. Sow plasma SA A, $\mathrm{Hp}$ and progesterone around farrowing were al so 19 assessed. Selected ear-tagged piglets were weighed at 3 to 4 weeks of age to calculate individual 20 average daily gain. Sow $\mathrm{CY}$ was positively correlated with plasma $\mathrm{Hp}(\mathrm{P}=0.029)$ and number of 21 live-born piglets $(P<0.01)$. A $n$ additional minute of farrowing duration lower the $C Y$ by $2.2 \mathrm{~g}(P=$ 22 0.01). Piglet $\mathrm{Cl}$ was positively associated with piglet weight at birth $(\mathrm{P}<0.001)$ and negatively 23 associated with the number of live-born piglets in the litter and percentage of protein in the 24 colostrum $(\mathrm{P}<0.001)$. B oth piglet $\mathrm{Cl}$ and birth weight were positively associated with piglet 
average daily gain $(A D G)(P<0.001)$. Piglet survival from birth to weaning depends on $\mathrm{Cl}$. We found that the risk for piglets death or a piglet being treated with antibiotic before weaning increase with a decrease in sow back fat thickness at farrowing $(P=0.04)$. Similarly, we found that piglets of litters with low $B W_{B}$ and low $\mathrm{Cl}$ had higher risk of death before weaning $(P<0.001)$. Piglets born from sows having lower levels of colostrum IgA and SA A and high plasma progesterone at the end of farrowing had higher risk of neonatal diarrhea $(P=0.04 ; P=0.05 ; P=0.04)$. Piglets born from sows having higher back fat thickness at weaning had higher risk of developing weaning diarrhea $(P=0.02)$. Sow body condition and physiological status around farrowing affect $C Y$ and colostrum Ig. Piglet survival and risk of death before weaning also depend on $\mathrm{Cl}$. Therefore, to support $\mathrm{CY}$ and $\mathrm{Cl}$, measures should be taken to ease the process of farrowing, increase piglet vitality and improve colostrum availability for piglets.

\section{Keywords}

Farrowing; Environment; A cute phase proteins; Piglet mortality; A ntibiotic

\section{Introduction}

Pre-weaning piglet mortality ranges from $10-13 \%$ in the principal pig-breeding countries (Ewdards, 2002; K ilbride et al. 2012) and it is well documented that insufficient colostrum intake (CI) is one of the major causes of mortality (Hales et al. 2014; Decaluwé et al. 2014). Studies reported that approximately $30 \%$ of hyper prolific sows produce insufficient colostrum for their litters Foisnet et al. 2010; Decal uwé et al. 2013), despite colostrum being the only source of energy and passive immunity for the neonate (Rooke and Bland 2002; Le Dividich et al. 2005). Hyper prolific sows apparently al so have a longer farrowing duration (Björkman et al. 2017) which could impair colostrum production. M ost pre-weaning mortality occurs during the first 3 days after birth (Le Dividich et al. 2005; Shankar et al. 2009; M uns et al. 2016) . Inadequate $\mathrm{Cl}$ by the piglet is a leading cause of mortality during the first days after birth due to hypoglycemia, and consequently 
hypothermia (Le Dividich et al. 2005). In addition, insufficient intake of maternally-derived immunoglobulins (Ig) has a negative effect on piglet health status, which has a carry-over effect on weight gain and survival (D ecal uwé et al. 2014; Quesnel et al. 2012; Declerck et al. 2016).

A ssessment of this issue at the farm level, can be complicated because sow colostrum yield (CY) and colostrum Ig content and composition may vary considerably among sows (D evillers et al. 2007; Declerck et al. 2015; Hasan et al. 2016). This variation can be attributed to sow, piglet and environmental features (Quesnel, 2011; Declerck et al. 2015; Declerck et al. 2017). A ssociations between changes in the energy reserves and $\mathrm{CY}$ in late gestating sows were reported by Decaluwé et al. (2013): they found that sow CY was negatively associated with late gestation loss of back fat and consequently with sows arriving at farrowing with a reduced body condition. Some studies have also shown that $\mathrm{CY}$ is independent of litter size, thus, a higher number of live-born piglets per litter resulted in a lower CI per piglet (D evillers et al. 2007; Declerck et al. 2015). We conducted our study in commercial piggeries. We measured some physiological parameters of the sows, $\mathrm{CY}$, colostrum composition, piglet $\mathrm{Cl}$ and their association with piglets growth and mortality until weaning. B ecause physiology of farrowing and colostrum production are strictly connected (A Igers and U vnäs-M oberg, 2007), it is feasible any health impairment or disturbance of the homeostasis right before and during the farrowing process can be detrimental to $\mathrm{CY}$. A certain degree of inflammation and tissue damage at farrowing are inevitable ( $M$ ainau and $M$ anteca, 2011), but if farrowing is too prolonged and complicated (dystocia, hormonal impairment, stress due to housing constriction) it can develop into a severe pathological state (M ainau and $M$ anteca, 2011). Disturbances in homeostasis due to inflammation, tissue injury during gestation and the farrowing process can induce a nonspecific acute phase response (Sorrells et al. 2007). We hypothesize that measuring some pig acute phase proteins (A PPs) would provide additional information on abnormal inflammatory or tissue damage effects at farrowing on $\mathrm{CY}, \mathrm{Ig}$ content and colostrum composition. A nother hypothesis was that large litters might have adverse effect on sows, such as longer 
74 farrowing duration, possibly altering sow physiology and increasing the risk for hormonal

75 disruptions and inflammation. We also hypothesized that a large litter size and longer farrowing

76 duration would be negatively associated with $\mathrm{CY}, \mathrm{Cl}, \mathrm{Ig}$ content, colostrum composition, piglet

77 survival and piglet growth until weaning.

78

79

80

81

82

83

84

85

86

87

88

89

90

91

92

93

94

95

96

97

\section{M aterials and methods}

The experimental protocol was approved by the $\mathrm{N}$ ational A nimal Experiment $\mathrm{B}$ oard in Finland (ESA VI, Regional State A dministrative A gency for Southern Finland, permission ESA VI/333/04.10.03/2011) and by the Dutch authority CCD (The study performed in the Netherlands did not require a special license under the Dutch A nimal Procedures A ct, decision 26.04.2017).

\subsection{Study population and experimental design}

The study was carried out in hers on six commercial pig farms, described as herds 1- 6 later in Tables 1 and 2 (five in Finland and one in the N etherlands). Four different sow breeding lines were represented in these farrow-to-finish herds: $\operatorname{DanA} v \mathbf{v l}(n=2)$, Topigs TN70 $(n=2)$, Duroc $x$ Norwegian Landrace $(n=1)$ and Topigs $20(n=1)$. The main herd characteristics are shown in Table 1, including sow breeds and the number of sows studied per herd. During pregnancy sows were loose housed and feed was served in individual feeding cages. A pproximately one week before expected farrowing the sows were transferred to the farrowing room, where they were housed individually either in farrowing crates ( $n=5$ herds) or a farrowing pen ( $n=1$ herd). In herd 6, sows were kept in getaway pens in a group farrowing system. Within a herd, sows were selected on the basis of start of farrowing on a first come first sample principle. Sows farrowed spontaneously and the researcher sampled all sows upon availability at farrowing. No restrictions on parity of the sows were imposed, but it was taken into account in that it was uniformly distributed across the different herds. Parturition was observed with minimal interference in the farrowing 
process. The farrowing duration was calculated based on the birth of the first piglet representing the beginning, and the expulsion of the last piglet the end. When a piglet was born, its back was dried with a paper towel, in order to allow the birth rank number to be marked on the back with a thick marker, and the birth weight $\left(\mathrm{BW}_{\mathrm{B}}\right)$ was taken. During the first $24 \mathrm{~h}$ from the start of birth, piglets were allowed to consume only maternal colostrum. No additional feed supplement was allowed before they had been weighed for $\mathrm{Cl}$ calculation ( $24 \mathrm{~h}$ after the start of farrowing. Six piglets from each litter were selected and ear-tagged based on $B W_{B}$ in a block of three categories, 2 piglets weighed $<1 \mathrm{~kg}, 2$ piglets $1.4-1.8 \mathrm{~kg}$ and 2 piglets $>1.8 \mathrm{~kg}$, representing small, normal and large piglets, respectively. Cross-fostering was allowed only after the $24 \mathrm{~h}$ weighing, but not for the six selected piglets, which stayed with their original mother until weaning. Litters were balanced according to the number of functional teats, as it is usually done in commercial farms.

\subsection{M easurements and definitions}

All ear-tagged piglets were individually weighed at birth, $24 \mathrm{~h}$ after the start of farrowing and before weaning (3-4 weeks of age). The CY was calculated as the sum of the individual piglet CIs within a litter, as described by Devillers et al. (2004), using the following variables: BW $\mathrm{B}_{\mathrm{B}}(\mathrm{kg})$, weight at 17 to $24 \mathrm{~h}$ of age ( $\mathrm{BW}_{24}, \mathrm{~kg}$ ), duration of $\mathrm{Cl}$ ( $\mathrm{t}$ in min and $17 \mathrm{~h} \mathrm{P}$ t P $24 \mathrm{~h}$ ), and time between birth and first suckling (tFS, $\mathrm{min}$ ). The regression equation was: $\mathrm{Cl}=-217.4+0.217 \times \mathrm{t}+$ $1861019 \times \mathrm{BW}_{24} / \mathrm{t}+\mathrm{BW} \mathrm{B}_{\mathrm{B}} \times(54.80-1861019 / \mathrm{t}) \times(0.9985-3.7 \times 10-4 \times \mathrm{tFS}+6.1 \times 10-7 \times \mathrm{t} 2 \mathrm{FS})$.

The tFS was estimated to be $35 \mathrm{~min}$, which was based on our observations from previous studies (Hasan et al. 2016) and was same as in a recent study (Decaluwé et al. 2013). A n error of 15 min in tFS will generate a $6 \mathrm{~g} / \mathrm{kg} \mathrm{BW}_{\mathrm{B}}$ miscalculation of $\mathrm{Cl}$ for piglets or less than $2 \%$ error (Devillers et al. 2004). Sow back fat was measured at the level of the last rib, 6 to $7 \mathrm{~cm}$ from one side of the backbone using a digital back-fat indicator (R enco lean-meater ${ }^{\circledR}$, R enco Corporation, M inneapolis, $M N, U S A)$ at farrowing $\left(B F_{F}\right)$ and at weaning $\left(B F_{W}\right)$. Observed sow parameters were: parity, gestation length, farrowing duration, back fat thickness at farrowing and weaning, and numbers of 
123 live-born and still born piglets. Gestation length was calculated based on day of first insemination

124 (start) and day of parturition. Observed piglet parameters were: $\mathrm{Cl}$, birth interval (time interval

125 between births of individual piglets), pre-weaning mortality, $B W_{B}, B W_{24}$, body weight at weaning,

126 and average daily gain (ADG) from birth to weaning, use of antibiotics (during the first week of

127 age), diarrhea within $24 \mathrm{~h}$ of birth and diarrhea during the first week of life (from $24 \mathrm{~h}$ of birth to 128 one week of age).

129

130

131

132

133

134

135

136

137

138

139

140

141

142

143

144

145

146

147

\subsection{Samples}

Twenty milliliters of colostrum were collected from each sow within the first two hours after birth of the first piglet. Colostrum samples were collected from the first three teats of same side of the anterior udder. Samples were aliquoted and stored at $-20^{\circ} \mathrm{C}$ until further analysis. Sow blood samples were collected from the vena saphena at the beginning and at the end of farrowing using lithium heparin tubes, and centrifuged at $1000 \times \mathrm{g}$ for 10 minutes, the plasma being separated, aliquoted and stored at $-20^{\circ} \mathrm{C}$ for further analysis. Blood samples were not collected from herd 6 .

\subsection{Analyses of samples}

The standardized and complete methods for measuring colostrum composition were described in (Hasan et al. 2016). Concentration of Ig was quantified using swine IgG, IgA and IgM ELISA quantification K its (B ethyl Laboratories, M ontgomery, Texas, USA). The intra- and interassay coefficients of variation were $4.8 \%, 3.3 \%, 1.3 \%$ and $6.7 \%, 5.3 \%, 6.8 \%$ for IgG IgA and IgM respectively. The colostrum total solid (TS), fat, protein and lactose contents were analyzed using M ilkoScanTM FT + (Foss, Hillerød, Denmark), according to a validated method described in previous study (Hasan et al. 2016). Colostrum and plasma serum amyloid A (SA A) were analyzed with commercial multispecies indirect ELISA (PhaseTM SAA A ssay, Tridelta Development Ltd., K ildare, Ireland) according to the manufacturer's instructions for swine. The intra- and inter-assay coefficients of variation were $12 \%$ and $12 \%$ respectively. Colostrum and plasma haptoglobin ( $\mathrm{Hp}$ ) concentrations were analyzed with a hemoglobin-binding assay developed for cows (M akimura and 
148 Suzuki, 1982) with modifications, in which tetramethylbenzidine was used as a substrate and $5 \mu$ las

149 a sample volume. Pooled and lyophilized aliquots of porcine acute phase serum were used as

150 standards. The assay was calibrated using a porcine serum sample of known $\mathrm{Hp}$ concentration

151 provided by the European Commission Concerted Action Project (number QLK 5-CT-1999-0153).

152 The intra- and inter-assay coefficients of variation were $8 \%$ and $11 \%$ respectively. Blood plasma

153 progesterone was analyzed using radioimmunoassay (RIA) (Progesterone I mmuChem, ICN

154 Pharmaceuticals, USA).

155

156

157

158

159

160

161

162

163

164

165

166

167

168

169

170

171

172

\subsection{Data processing and statistical analysis}

A sow level dataset (outcome variables measured at sow level) was used to study sow level variable associations between farrowing data and colostrum quality. Tree level hierarchical mixed linear regression models were built to study variables associated with sow level continuous outcome variables (farrowing duration, number of born piglets, CY, colostrum IgG IgA and IgM concentrations). Square root transformation (for colostrum IgA and IgM ) and logarithmic transformation (for colostrum IgG and farrowing duration) were used to achieve normal distribution of outcome variables. Farm and trial batch within the farm were included as random factors in all models.

For model building, univariate analyses with explanatory variables were performed. Explanatory variables with P P 0.2 were included in the "full models". Full model for farrowing duration included average piglets $B W_{B}(g)$, back fat at farrowing $(\mathrm{mm})$, number of born piglets as continuous, and progesterone at farrowing $2 \mathrm{PF}$ and $>6 \mathrm{ng} / \mathrm{ml})$ and parity category $(1-2,3-5$ and $>5)$ as categorical explanatory variables. Full model for number of born piglets included gestation length (days) and back fat at farrowing as continuous, and parity category as categorical explanatory variables. The full model for $\mathrm{CY}$ included farrowing duration ( $\mathrm{min}$ ), plasma $\mathrm{Hp}(\mathrm{mg} / \mathrm{l}$ ) and number of born piglets as continuous, and parity category as categorical explanatory variables. The full model for colostrum IgG included plasma SAA (mg/l) as continuous and feed and parity 
173 category as categorical explanatory variables. The full model for IgA included farrowing duration

174 and back fat at farrowing as continuous and parity category as categorical explanatory variables.

175 The full model for IgM included plasma SA A, plasma $\mathrm{Hp}$ and farrowing duration as continuous, 176 and parity category as categorical explanatory variables.

177 Stepwise backward elimination procedure was performed for final models. Linear 178 relationship between outcome and continuous explanatory variables and squared explanatory 179 variable was included (after centring to avoid collinearity) into the model when appropriate. 180 B iologically meaningful interactions were checked. Possible confounding variables were tested 181 (cofounding was defined as 15\% change in variable coefficient). Collinearity between explanatory 182 variables was explored using corresponding VIF values. A ssumptions for all linear mixed models 183 were confirmed using normality and scatter plots of model residuals. Similar tree level mixed logit models were used to study associations among explanatory variables with dichotomous outcome variables (antibiotic treatment of sow or piglets - yes/no and litter diarrhea at $24 \mathrm{~h}$ post-partum - yes/no) in the sow level dataset. Farm and trial batch inside the

187 farm were included as random factors. A fter univariate analysis final models were built similarly to the linear mixed models described above. The full model for antibiotic treatment of sow or piglets included number of live-born piglets, back fat at farrowing, back fat at weaning, plasma $\mathrm{Hp}$, litter weight at $24 \mathrm{~h}(\mathrm{~g})$ and colostrum $\mathrm{lg}(\mathrm{mg} / \mathrm{ml})$ as continuous, and parity category as categorical

191 explanatory variables. The full model for litter diarrhea at $24 \mathrm{~h}$ post-partum included average piglet $192 \mathrm{BW}_{\mathrm{B}}$ and colostrum SAA as continuous, and progesterone at the beginning of farrowing $2 \mathrm{PF}$ and $>6$ $\mathrm{ng} / \mathrm{ml}$ ) as categorical explanatory variables. The level of progesterone was considered higher when $6.0 \mathrm{ng} / \mathrm{ml}$ and $>4.9 \mathrm{ng} / \mathrm{ml}$, at the beginning and end of farrowing respectively (describing an increase of $50 \%$ of the respective average levels found in this study). 
198 levels. Piglet within sow, sow within trial batch, trial batch within farm and farm were included as 199 random factors. Similarly to the sow level models, final models were built after initial univariate 200 analysis. The full model for $\mathrm{Cl}$ included farrowing duration, piglet $\mathrm{BW}_{\mathrm{B}}$, number of born piglets, 201 colostrum H p, colostrum protein (\%) and colostrum IgG as continuous, and sow feed and piglet 202 birth order as categorical explanatory variables. The full model for piglets ADG at 3-4 weeks of age 203 included piglet BW B, piglet age at weighing (days), CI (g) categories ( P 200, 201-250, 251-350, Y 351) farrowing duration, number of live-born piglets, colostrum SAA and colostrum fat (\%) as continuous, and piglet birth order as categorical explanatory variables. The $\mathrm{Cl}$ categories were made following the categories mentioned in (Q uesnel at al. 2012).

Similar four level mixed logit models were used for piglet level dichotomous outcome variables (death before weaning, diarrhea at 7 days of age - yes/no and diarrhea at weaning yes/no). The full model for death before weaning included piglet $\mathrm{BW} \mathrm{B}_{\mathrm{B}}, \mathrm{Cl}$, number of born piglets and back fat at farrowing as continuous explanatory variables. The full model for diarrhea at 7 days of age included number of stillbirth piglets, plasma $\mathrm{Hp}$, colostrum IgA and back fat at farrowing as continuous, and litter diarrhea at $24 \mathrm{~h}$ post-partum (yes/no) and progesterone at farrowing 2PF and $>6 \mathrm{ng} / \mathrm{ml}$ ) as categorical explanatory variables. The full model for diarrhea at weaning included back fat at weaning, colostrum IgM and piglet $\mathrm{BW}_{\mathrm{B}}$ as continuous explanatory variables. $\mathrm{All}$ the same model-building strategies were used as in the sow level mixed linear and logistic models.

W e performed the statistical analysis with the Stata 14.0 (StataCorp, TX) and SPSS 24.0 software (IB M , Chicago, IL; USA) considering a P-value P 0.05 as being statistically significant.

\section{Results}

\subsection{Descriptive results}

In total, 229 sows with 3,210 live-born piglets were included in the study. Sows had an average parity of $3.5 \pm 0.1$ (mean $\pm S E M$; range 1 to 8 ) and an average gestation length of $115.2 \pm$ 
0.07 (112 to 119 ) days. On average farrowing lasted $265.1 \pm 9.8 \mathrm{~min}$. Number of stillborn piglets was $1.1 \pm 0.1$. Litter size averaged $15.0 \pm 0.2$ live-born piglets, with average birth weight of 1338.2 $\pm 5.8 \mathrm{~g}$, weaning weight $7229.9 \pm 45.3 \mathrm{~g}$, and A D G from birth to weaning $236.1 \pm 1.8 \mathrm{~g}$. At the herd level, descriptive data for the outcome and predictor variables are summarized in Table 2.

\subsection{Sow back fat, blood parameters and physiology}

A verage sow back fat was $20.6 \pm 0.3 \mathrm{~mm}(10.0$ to $36.0 \mathrm{~mm}$ ) and $16.7 \pm 0.3 \mathrm{~mm}$ (6.0 to 30.0 $\mathrm{mm}$ ) at farrowing and weaning respectively. Plasma $\mathrm{Hp}$ and SA A were $1882.8 \pm 42.4 \mathrm{mg} / \mathrm{l}$ and 19.6 $\pm 2.2 \mathrm{mg} / \mathrm{l}$ respectively.

\subsection{Sow farrowing characteristics, colostrum yield and colostrum composition}

A verage $\mathrm{CY}$ per sow was $4,346.1 \pm 84.8 \mathrm{~g}$ (766 to 9,239 g). A verage sow colostrum IgG, IgA and IgM were $80.0 \pm 1.9,10.3 \pm 0.2$ and $4.9 \pm 0.1 \mathrm{mg} / \mathrm{ml}$ respectively. A verage sow colostrum protein, fat and lactose percentage were $16.6 \pm 0.1,4.5 \pm 0.1$ and $4.5 \pm 0.1$, respectively. The result of multivariate linear mixed regression analyses with sow colostrum and farrowing characteristics are summarized in Table 3. The regression analysis revealed that the factors associated with $\mathrm{CY}$ were: plasma $\mathrm{Hp}$, farrowing duration and live-born piglets. A $\mathrm{n}$ additional individual live-born piglet increased the $\mathrm{CY}$ by $93.6 \mathrm{~g}(\mathrm{P}<0.01)$. On the other hand, an additional minute of farrowing duration lower the $\mathrm{CY}$ by $2.2 \mathrm{~g}(\mathrm{P}=0.01)$. However, sow plasma $\mathrm{Hp}$ level positively correlated with sow CY $(P<0.05)$. Sow colostrum Ig content (which included IgG, IgA and IgM) was significantly influenced by sow parity, with older sows having a higher immunoglobulin content, except for IgM (which was lower in parities over 5). In addition, sow back fat at farrowing was positively correlated with colostrum IgA level $(P<0.01)$. M oreover, older sows (parity over 5 ) had a significantly larger litter size (live-born) and longer farrowing duration than the younger sows.

The average progesterone level in each herd is described in Figure 1. Sow average plasma progesterone level at start of farrowing was $3.8 \pm 0.2 \mathrm{ng} / \mathrm{ml}$ and at the end $3.2 \pm 0.2 \mathrm{ng} / \mathrm{ml}$. Fifteen 
percent of the sows had $50 \%$ higher plasma progesterone than the average level at the beginning of 247 farrowing. M oreover, at the end of the farrowing some of the sows ( $n=24$ ) still had $50 \%$ higher 248 than the average progesterone level in plasma at that stage. However, we did not establish 249 significant relationship between $\mathrm{CY}$ with progesterone level around farrowing in the multivariable 250 regression analysis, including herd as a random factor.

251

252

253

254

255

256

257

258

259

260

261

262

263

264

265

266

267

268

269

270

\subsection{Piglet colostrum intake in relation to growth and mortality}

Piglet average $\mathrm{Cl}$ was $308.9 \pm 2.7 \mathrm{~g}$ ( 0 to $955 \mathrm{~g}$ ). Thirty six percent of the piglets received less than $250 \mathrm{~g}$ of colostrum and $23 \%$ percent of piglets received less than $200 \mathrm{~g}$ of colostrum. Piglet $\mathrm{Cl}$ was associated with body weight of piglet at birth, live-born litter size and colostrum protein concentration (Table 4). The $\mathrm{Cl}$ increased by $0.19 \mathrm{~g}(\mathrm{P}<0.001)$ for $1 \mathrm{~g}$ of $\mathrm{BW}_{\mathrm{B}}$. On the other hand, $\mathrm{Cl}$ was negatively associated with number of live-born piglets, decreasing by $9.4 \mathrm{~g}$ for each additional live-born piglet $(P<0.001)$. Similarly, for an increase of one percentage unit of colostrum protein, piglet $\mathrm{Cl}$ decreased by $5.7 \mathrm{~g}(\mathrm{P}<0.001)$. B oth piglet $\mathrm{Cl}$ and birth weight were positively associated with piglet ADG (birth to weaning), a $\mathrm{Cl}$ of $1 \mathrm{~g}$ was associated with an increase in ADG of $0.13 \mathrm{~g}$ until weaning $(P<0.001)$. However, for piglets dying or surviving until weaning, colostrum intake averaged $203.6 \pm 11.6 \mathrm{~g}$ and $339.5 \pm 3.5 \mathrm{~g}$ respectively $(P<0.001$;

Figure 2). W eaning weights and growth (ADG) of the piglets were related to $\mathrm{Cl}$ independently of $\mathrm{BW}_{\mathrm{B}}(\mathrm{P}=0.001)$. If a piglet consumed $\mathrm{P} 200 \mathrm{~g}$ of colostrum and managed to survive, its growth was on average the lowest, while proportionally higher $\mathrm{Cl}$ correlated with higher weaning weight (Figure 3).

\subsection{Sow back fat and piglet colostrum intake with relation to diarrhea and antibiotic}

\section{treatment}

All the models regarding piglet mortality, diarrhea and antibiotic use are presented in Table 5. We found that the lower the sow back fat thickness at farrowing the higher was the risk for piglets to die and/or for piglets to be treated with antibiotic before weaning ( $O R=0.923$; 
271 Confidence Interval $=0.854-0.997 ; \mathrm{P}=0.04$ and $\mathrm{OR}=0.782 ;$ Confidence Interval $=0.630$ -

$2720.970 ; P=0.02$ respectively). Similarly, the lower the average litter $B W_{B}$ and the lower the average 273 litter $\mathrm{Cl}$ during the first $24 \mathrm{~h}$ of life, the higher was the risk for piglets death before weaning $(\mathrm{OR}=$ 274 0.998; Confidence Interval $=0.998-0.999 ; P<0.001$ and $O R=0.994 ;$ Confidence Interval $=0.992$ $275-0.997 ; \mathrm{P}<0.001$ respectively). On the other hand, the higher the back fat thickness at weaning, 276 the higher was the risk for piglet to have weaning diarrhea $(\mathrm{OR}=1.18 ; \mathrm{Cl}=1.02-1.37 ; \mathrm{P}=0.02)$. 277 The lower the IgA colostrum level, the higher was the risk of piglet to develop diarrhea during their 278 first week of life $(\mathrm{OR}=0.771 ; \mathrm{Cl}=0.598-0.993 ; \mathrm{P}=0.04)$, while the lower the level of colostrum 279 SA A the higher was the risk of piglet litter diarrhea during the first day of their life $(\mathrm{OR}=0.998 ; \mathrm{Cl}$ $280=0.995-1.0 ; P=0.05)$. However, piglets born from sows having more than $50 \%$ higher level of 281 sow plasma progesterone at the end of farrowing $(>4.9 \mathrm{ng} / \mathrm{ml})$, the higher was the risk of litter 282 diarrhea during the first day of their life $(O R=3.71 ; C l=1.04-13.23 ; P=0.04)$.

\section{Discussion}

A prolonged duration of farrowing and low $\mathrm{Hp}$ in sow plasma decreased sow $\mathrm{CY}$.

M oreover, sow parity had effects on colostrum Ig content and older sows (parity over 5) had more IgG and IgA in their colostrum than younger sows. Sows with thicker back fat at farrowing had higher colostrum IgA . In addition, piglet CI was correlated with ADG and survivability until weaning. We also found that piglet antibiotic treatment and survival until weaning were negatively associated with back fat thickness of the sow at farrowing. Earlier studies (D evillers et al. 2011;

Decaluwé et al. 2014) reported that sow CY and piglet $\mathrm{Cl}$ were positively associated with

survivability and weight gain during the first 6 weeks of life, stressing the importance of colostrum availability and intake for piglets. We noted in our study that $36 \%$ of the piglets got less than $250 \mathrm{~g}$ of colostrum, and $23 \%$ percent of piglets got less than $200 \mathrm{~g}$ of colostrum. We established (Fig. 2) 
when piglets ingest more than $200 \mathrm{~g}$ and can be increased up to $43.4 \%$ when intake is less than 200

297 g. Weaning weights of the piglets were found to be dependent on CI(Decaluwé et al. 2014). Our

298 findings support the suggestion that a minimum average amount of $250 \mathrm{~g}$ colostrum intake is

299 recommended to achieve good growth and body weight before weaning (Quesnel et al. 2012), as it

300 is showed in figure 3.

301

Sow CY in this study was comparatively higher than in studies done previously, calculated

302

303

304

305

306

307

308

309

310

311

312

313

314

315

316

317

318

319

320 using the same method (Quesnel, 2011; Decaluwé et al. 2013; Decaluwé et al. 2014; Declerck et al. 2015). Sow CY is highly variable and this variation can be attributed to sows, piglets,

environmental traits and herd management (Quesnel, 2011; Declerck et al. 2015; Declerck et al. 2017; D evillers et al. 2007). In the present study, the variability of CY among different parity groups was not significant, supporting previous findings (Quesnel, 2011; Declerck et al. 2015). This is in contrast with Devillers et al. (2007) who reported that second and third parity sows produces more colostrum than primiparous and older sows. Also Decaluwé et al. (2013) found that sows of parities one and three produced more colostrum than other parity sows.

In our study, CY was significantly associated with litter size. This observation is not in accordance with previous studies (Quesnel, 2011; Devillers et al. 2007), possibly because in recent years litter size has been constantly increasing and those reference studies are now old and were based on smaller litter size than are currently the case. Sow farrowing duration was relatively longer than in earlier studies (Declerck et al. 2015; Devillers et al. 2007). This was probably due to the larger litter size in our studies, as it has been found that farrowing duration is significantly influenced by the litter size and number of stillborn piglets (Oliviero et al. 2010; Björkman et al. 2017). Interestingly, we established that CY was negatively associated with farrowing duration, although previous studies did not report this correlation (Devillers et al. 2007; Foisnet et al. 2010; Declerck et al. 2015). This could be explained by hormonal changes, because the durations of farrowing and colostrum production are mainly regulated by hormones and therefore sow 
321 physiological condition could be influential (A Igers and U vnäs-M oberg, 2007). Several hormones

322 regulate the both onset and the progress of farrowing and colostrum production, namely

323 progesterone, prolactin and oxytocin. During longer farrowing duration, opioids (due to a pre-

324 existing stress condition) might inhibit oxytocin and prolactin secretion (J arvis et al. 1997), and

325 thereby also reducing the $\mathrm{CY}$. H ow ever, progesterone, which remains at a high concentration

326 throughout the entire pregnancy, should decrease markedly with the approach of parturition while

327 prolactin increases (A Igers and U vnäs-M oberg, 2007). In the case that sows at farrowing experience

328 a delayed decrease in progesterone concentrations, and thereby a delayed increase in prolactin, this

329 might explain the lower levels of colostrum (F oisnet et al. 2010; Quesnel et al. 2012).

A decrease in plasma progesterone and a rise in plasma concentration of prolactin prior to

331 farrowing are known to initiate nest building behavior in prepartum sows (A Igers and U vnäs-

332 M oberg, 2007). Y un et al. (2014) demonstrated that onset of nest building, by providing abundant

333 nesting materials and space, was accompanied by an increased in plasma oxytocin concentration in

334 prepartum sows. M oreover, the study of $Y$ un et al. (2014) confirmed that for sows in a non-crated

335 system a plentiful supply of nesting materials prior to parturition tended to increase piglet serum

336 IgG and IgM concentrations during early lactation. A Ithough it was not the primary purpose of this 337 study to investigate housing condition at farrowing, it is very interesting that the average

338 progesterone levels were numerically lowest in the herds where sows had unlimited access to nest

339 building materials and sows were loosely housed in pens (herd 6). M eanwhile, the average

340 progesterone level was higher in those herds in crate housing and in which sows had limited access

341 to or no nesting material (Fig. 1). This is in line with Y un et al. (2014) and Farmer (2016),

342 suggesting that nesting materials and space for the movement of the sow may be beneficial for

343 improving colostrum production, successful $\mathrm{Cl}$ by piglets and ensure better quality colostrum. The

344 fact we could not establish an association between progesterone level and CY, could be due to the

345 average progesterone level at farrowing being higher in this study than previously reported (Foisnet 
et al. 2010). In the present study, the higher plasma progesterone at the end of farrowing also

347 increased the risk of neonatal piglet diarrhea at first day of life. This is probably because at each

348 single herd level the higher than average progesterone level and lower use of nesting material were

349 associated with a detrimental effect on sow colostrum quality as published previously (F oisnet et al.

350 2010; Y un et al. 2014 ). Piglets are born without immunity and colostrum provides the

351 immunological protection Rooke and Bland, 2002). Therefore, we can assume that litters of sows

352 with higher plasma progesterone suffered from neonatal diarrhea because of lower immunoglobulin

353 intake. This is supported by our findings that higher colostrum IgA content reduces the incidence of

354 piglet diarrhea during the first week of their life. B eyond the neonatal period, the supply of maternal

355 immunity and bioactive compounds by colostrum is relatively more important (Rooke and Bland

356 2002; Le Dividich et al. 2005).

357

At farrowing, sows undergo not only hormonal changes, but also substantial metabolic and

physiological changes occur during this very short period of time (A Igers and U vnäs-M oberg, 2007)

including tissue damage and inflammation response due to the parturition process ( $M$ ainau and

M anteca, 2011). Therefore, we studied sow APPs as markers of acute phase response in colostrum

and plasma. The acute phase response in sows can appear as nonspecific to disturbances in

homeostasis due to inflammation, tissue injury during gestation and farrowing (Sorrels et al. 2007).

Our current finding shows that sow plasma $\mathrm{Hp}$ concentrations were positively associated with $\mathrm{CY}$.

This association may not be directly related to the inflammation process, but it is more a reflection

of $\mathrm{Hp}$ function as a hemoglobin binding protein (Eaton et al. 1982). Tissue damage (and hemolysis)

can initially cause a decrease in serum $\mathrm{Hp}$ concentrations before the inflammatory stimulus initiates

367 the Hp production in the liver. Studies with calves showed decreased Hp concentrations in the case

368 of low-grade Eimeria infection (Seppä-L assila et al. 2015) and during transportation (A rthington et

369 al. 2003). Thus in our study, the lower plasma $\mathrm{H} p$ at farrowing associated with sows having lower

370 CY may be connected to the start of an inflammatory process, for example due to longer farrowing 
371 causing more tissue damage, hemolysis and depletion of circulating $\mathrm{Hp}$. W e found that high

372 colostrum SA A tended to be linked to reduced neonatal piglet diarrhea incidence during first day of

373 their life. A ge-dependent studies showed that SA A plasma concentration is highest in neonate

374 piglets (M oya et al. 2007) and calves (Orro et al. 2008). Higher colostrum SA A concentrations were 375 associated with higher serum SA A concentrations of lambs at 1-5 days of age (Peetsalu et al. 2019).

376 The function of SAA abundance in colostrum was suggested by L arson et al. (2003) to have a local

377 beneficial effect on the neonatal gut. They found that colostrum-associated SA A peptide enhanced

378 innate protection by stimulating intestinal epithelial cells and mucous production, thereby

379 preventing binding of enteropathogenic bacteria. This could explain our findings between high SAA

380 in colostrum and reduced piglet diarrhea. Interestingly, in a recent study we found that

381 supplementing sow diet with resin acid-enriched composition (RAC) tended to increase the sow

382 colostrum SAA (Hasan et al. 2018). On the basis of the results of the present study, higher SA A

383 content in colostrum could be seen as a positive feature for improving piglet survival. Sow body

384 condition at farrowing has significant influence on CY. Decal uwé et al. (2013) reported that the sow

385 back fat changes at the end of gestation were negatively associated with sow $\mathrm{CY}$. O ur studies

386 revealed that sow back fat thickness at farrowing is positive correlated with colostrum IgA,

387 underlining the importance of fit sows at the start of lactation, avoiding excessive leanness. Studies

388 also revealed a significant correlation between sow back fat during lactation and piglet survival and

389 growth (G randinson et al. 2005). Our present findings, on back fat thickness and colostrum IgA

390 content confirms previous studies where high enough level of sow body reserves are considered

391 important at the start of lactation for the piglets growth and survivability (G randinson et al. 2005).

\section{Conclusion}

In conclusion we found that extended farrowing can be detrimental for colostrum yield.

394 Easing the farrowing process, by allowing more space and providing nesting materials, could

395 therefore be benefit for piglet survival and growth. In this study we confirmed also that $\mathrm{CI}$ was 
396

397 398 399 400 401 402 403 404 during the trials.

405 References

406 2007.

positively correlated with survivability and ADG of piglets until weaning. Sows with higher back

fat at farrowing had higher levels of IgA in colostrum, and piglets from such sows were at less risk to die and to be treated with antibiotic until weaning. M oreover, we found that SA A and IgA in colostrum had beneficial influence on reducing piglet diarrhea.

\section{A cknowledgement}

This research was financially supported by the Finnish M inistry of A griculture and Forestry, COL PIM O project, 1803/312/2014. The authors wish to acknowledge M erja Pöytäkangas for providing expert technical assistance in laboratory analysis, and all pig farmers for their support

A lgers B, U vnäs-M oberg K. M aternal behavior in pigs. Horm. B ehav. 2007;52(1):78-85.

A rthington JD, Eicher SD, K unkle WE, M artin FG. Effect of transportation and commingling on the acute-phase protein response, growth, and feed intake of newly weaned beef calves. J . A nim. Sci. 2003;81(5):1120-5.

Björkman S, Oliviero C, Rajala-Schultz PJ, Soede N M, Peltoniemi O. The effect of litter size, parity and farrowing duration on placenta expulsion and retention in sows. Theriogenology 2017;92:36-44.

Decal uwé R, M aes D, Declerck I, Cools A, W uyts B, De Smet S, et al. Changes in back fat thickness during late gestation predict colostrum yield in sows. A nimal 2013;7(12):1999- 
416 Decaluwé R, M aes D, W uyts B, Cools A, Piepers S, J anssens G PJ. Piglets \ colostrum intake 417 associates with daily weight gain and survival until weaning. Livest. Sci. 2014;162:185-92.

418 Declerck I, Dewulf J, Piepers S, Decaluwé R, M aes D. Sow and litter factors influencing colostrum 419 yield and nutritional composition. J. A nim. Sci. 2015;93(3):1309-17.

420 Declerck I, Dewulf J, Piepers S, Decaluwé R, M aes D. Sow and litter factors influencing colostrum 421 yield and nutritional composition. J. A nim. Sci. 2015;93(3):1309-17.

422 Declerck I, Dewulf J, Sarrazin S, M aes D. L ong-term effects of colostrum intake in piglet mortality 423 and performance. J. A nim. Sci. 2016;94(4):1633-43.

424 Declerck I, Sarrazin S, Dewulf J, M aes D. Sow and piglet factors determining variation of 425 colostrum intake between and within litters. A nimal 2017;11(8):1336-43.

426 Devillers N, Farmer C, Le Dividich J, Prunier A . V ariability of colostrum yield and colostrum $427 \quad$ intake in pigs. A nimal 2007;1(7):1033-41.

428 Devillers N, Farmer C, Le Dividich J, Prunier A . V ariability of colostrum yield and colostrum 429 intake in pigs. A nimal 2007;1(7):1033-41.

430 Devillers N, Le Dividich J, Prunier A I Influence of colostrum intake on piglet survival and $431 \quad$ immunity. A nimal 2011;5(10):1605-12.

432 Devillers N, V an M ilgen J, Prunier A, L e Dividich J. Estimation of colostrum intake in the neonatal 433 pig. A nim. Sci. 2004;78(2):305-13.

434 Eaton JW , B randt P, L ee JT. Haptoglobin: A natural bacteriostat. Science 1982;215(4533):691-3. 
435 Edwards SA. Perinatal mortality in the pig: Environmental or physiological solutions? Livest. Prod. Sci. 2002;78(1):3-12.

Farmer C. A Itering prolactin concentrations in sows. Domest. A nim. Endocrinol. 2016;56:S164.

438

439

440

441

442

443

444

445

446

447

448

449

450

451

452

453

454

Foisnet A , Farmer C, David C, Quesnel H. Relationships between colostrum production by primiparous sows and sow physiology around parturition. J. A nim. Sci. 2010;88(5):1672-83.

Grandinson K, Rydhmer L, Strandberg E, Solanes FX. Genetic analysis of body condition in the sow during lactation, and its relation to piglet survival and growth. A nimal Science 2005;80(1):33-40.

Hales J, M oustsen VA, Nielsen M, Hansen CF. Higher preweaning mortality in free farrowing pens compared with farrowing crates in three commercial pig farms. A nimal 2014;8(1):113-20.

Hasan S, J unnikkala S, Valros A, Peltoniemi O, Oliviero C. V alidation of brix refractometer to estimate colostrum immunoglobulin $\mathrm{G}$ content and composition in the sow. A nimal 2016;10(10):1728-33.

Hasan S, Saha S, J unnikkala S, Orro T, Peltoniemi O, Oliviero C. L ate gestation diet supplementation of resin acid-enriched composition increases sow colostrum immunoglobulin $\mathrm{G}$ content, piglet colostrum intake and improve sow gut microbiota. A nimal 2018:1-8.

J arvis S, Lawrence A B, M CL ean KA, Deans LA, Chirnside J, Calvert SK. The effect of environment on behavioural activity, "2^ 8 and cortisol in pre-farrowing gilts. A nim. Sci. 1997;65(3):465-72. 
455 Kilbride A L, M endl M, Statham P, Held S, Harris M, Cooper S, et al. A cohort study of preweaning

456

457

458

459

460

461

462

463

464

465

466

467

468

469

470

471

472

473

474 Orro T, Jacobsen S, LePage J, N iewold T, A lasuutari S, Soveri T. Temporal changes in serum 475 piglet mortality and farrowing accommodation on 112 commercial pig farms in england. Prev. V et. M ed. 2012;104(3-4):281-91.

Larson M A, W ei SH, W eber A, M ack DR, M cD onald TL. Human serum amyloid A 3 peptide enhances intestinal MUC3 expression and inhibits EPEC adherence. Biochem. Biophys. Res. Commun. 2003;300(2):531-40.

Le Dividich J, Rooke JA, Herpin P. N utritional and immunological importance of colostrum for the new-born pig. J. A gri. Sci. 2005;143(6):469-85.

M ainau E, M anteca X. Pain and discomfort caused by parturition in cows and sows. A ppl. A nim. Behav. Sci. 2011;135(3):241-51.

M akimura S, Suzuki N. Quantitative determination of bovine serum haptoglobin and its elevation in some inflammatory diseases. Japan. J. V et. Sci. 1982;44(1):15-21.

M oya SL, B oyle LA, Lynch PB, A rkins S. A ge-related changes in pro-inflammatory cytokines, acute phase proteins and cortisol concentrations in neonatal piglets. Neonatology 2007;91(1):44-8.

M uns R, N untapaitoon M, Tummaruk P. N on-infectious causes of pre-weaning mortality in piglets. Livest. Sci. 2016;184:46-57.

Oliviero C, Heinonen M , V alros A, Peltoniemi O. Environmental and sow-related factors affecting the duration of farrowing. A nim. Reprod. Sci. 2010;119(1-2):85-91. concentrations of acute phase proteins in newborn dairy calves. V et. J. 2008;176(2):182-7. 
Peetsalu K, Tummeleht L, Kuks A, Orro T. Serum amyloid A and haptoglobin concentrations in relation to growth and colostrum intake in neonatal lambs. Livest Sci. 2019; 220: 217-220.

Quesnel H, Farmer C, Devillers N. Colostrum intake: Influence on piglet performance and factors of variation. Livest. Sci. 2012;146(2-3):105-14.

Quesnel H. Colostrum production by sows: V ariability of colostrum yield and immunoglobulin G concentrations. A nimal 2011;5(10):1546-53.

Rooke JA, Bland IM. The acquisition of passive immunity in the new-born piglet. Livest. Prod. Sci. 2002;78(1):13-23.

Seppä-L assila L, O rro T, Lassen B, Lasonen R, A utio T, Pelkonen S, et al. Intestinal pathogens, diarrhoea and acute phase proteins in naturally infected dairy calves. Comp. Immunol. Microbiol. Infect. Dis. 2015;41:10-6.

Shankar B P, M adhusudhan HS, Harish D B. Pre-weaning mortality in pig-causes and management. V et. W orld 2009;2(6): 236-239.

Sorrells A D, Eicher SD, Harris MJ, Pajor EA, Richert BT. Periparturient cortisol, acute phase cytokine, and acute phase protein profiles of gilts housed in groups or stalls during gestation. J. A nim. Sci. 2007;85(7):1750-7.

Y un J, Swan KM, Vienola K, Kim YY, Oliviero C, Peltoniemi O, et al. Farrowing environment has an impact on sow metabolic status and piglet colostrum intake in early lactation. Livest. Sci. 2014;163:120-5.

\section{Figure captions}

Figure 1. M ean and SEM plasma progesterone in five herds at the beginning of farrowing. 
497

498 ** L imited amount of nesting material in farrowing crate (2-4 liters of saw dust and/or straw)

$499 *$ No nesting material in farrowing crate

500 Figure 2. Piglet colostrum intake and survivability until weaning .M ean \pm SEM

501 Figure 3. Correlation between A DG and different colostrum intake categories, with respective 502 indicative average weight at 3-4 weeks found in this study piglets population. M ean \pm SEM

504

505

506

507

508

509

510

511

512

513

514

515

516 
517 Table 1. Specific information for individual herd. M ean \pm SEM

\begin{tabular}{|c|c|c|c|c|c|c|}
\hline & \multicolumn{6}{|c|}{ Herd number } \\
\hline & 1 & 2 & 3 & 4 & 5 & 6 \\
\hline Country & $\mathrm{FI}$ & $\mathrm{Fl}$ & $\mathrm{Fl}$ & $\mathrm{Fl}$ & $\mathrm{NL}$ & $\mathrm{FI}$ \\
\hline Sow breed & $\begin{array}{l}\text { Topigs } \\
\text { TN70 }\end{array}$ & $\begin{array}{l}\text { Topigs } \\
\text { TN70 }\end{array}$ & DanA vl & DanAvl & $\begin{array}{c}\text { Topigs } \\
20\end{array}$ & $\mathrm{DU} \times \mathrm{NL}$ \\
\hline Number of sows & 44 & 47 & 39 & 20 & 60 & 20 \\
\hline $\begin{array}{l}\text { Number of } \\
\text { batches }\end{array}$ & 4 & 8 & 9 & 5 & 2 & 3 \\
\hline Sow parity & $3.8 \pm 0.2$ & $3.6 \pm 0.3$ & $3.3 \pm 0.3$ & $3.5 \pm 0.4$ & $3.1 \pm 0.1$ & $3.6 \pm 0.4$ \\
\hline 1 to 2 & 9 & 16 & 18 & 7 & 21 & 7 \\
\hline $3-5$ & 27 & 23 & 14 & 9 & 35 & 9 \\
\hline Over 5 & 8 & 8 & 7 & 4 & 4 & 4 \\
\hline $\begin{array}{l}\text { Housing at } \\
\text { farrowing }\end{array}$ & Crate & Crate & Crate & Crate & $\begin{array}{l}\text { Crate and } \\
\text { pen }\end{array}$ & pen \\
\hline Feeding & $\begin{array}{l}\text { Standard } \\
\text { lactation }\end{array}$ & $\begin{array}{l}\text { Standard } \\
\text { lactation }\end{array}$ & $\begin{array}{l}\text { Standard } \\
\text { lactation }\end{array}$ & $\begin{array}{l}\text { Standard } \\
\text { lactation }\end{array}$ & $\begin{array}{l}\text { Standard } \\
\text { lactation }\end{array}$ & $\begin{array}{l}\text { Standard } \\
\text { lactation }\end{array}$ \\
\hline Nesting material & No & Some* & Some* & No & Some* & Plenty** \\
\hline
\end{tabular}

$518 \mathrm{FI}=\mathrm{Finl}$ and; $\mathrm{NL}=\mathrm{N}$ etherland; $\mathrm{DU} \times \mathrm{NL}=\mathrm{Duroc} \times \mathrm{N}$ orwegian L andrace

$519 * 2-4$ liters (saw dust and/or straw)

$520 * *$ The whole pen floor with $15-20 \mathrm{~cm}$ of straw

521

522

523

524

525

526

527

528

529

530

531

532 
533 Table 2. Descriptive result of individual herd. Data presented in mean \pm SEM .

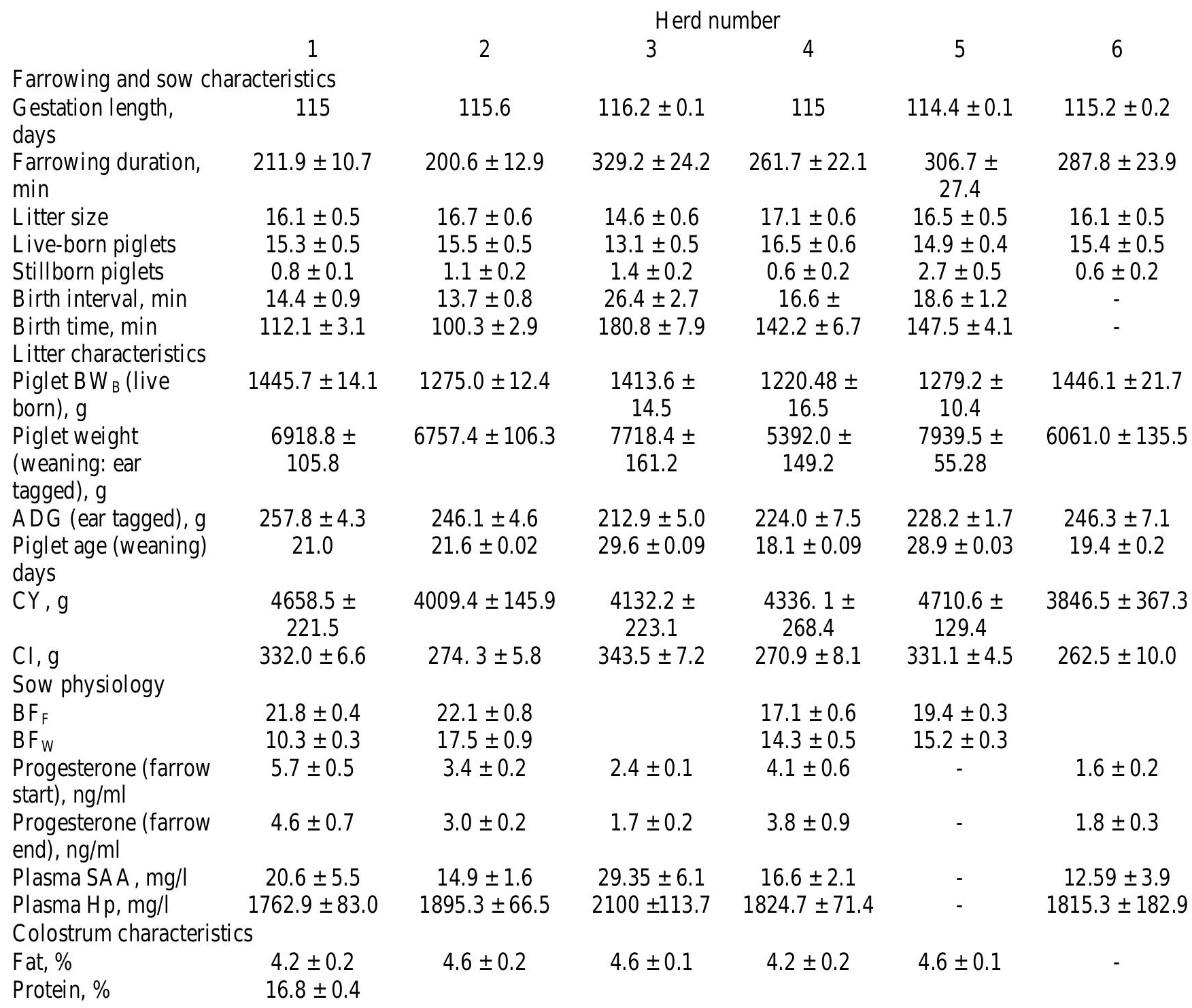








